\title{
PROCESOS EDUCATIVOS Y EL DERECHO A LA EDUCACIÓN: UNA MIRADA A PARTIR DE LOS RELATOS DE UNA INMIGRANTE HAITIANA EN BRASIL SOBRE EL EJERCICIO DOCENTE
}

\section{EDUCATIONAL PROCESSES AND THE RIGHT TO EDUCATION: A PERSPECTIVE FROM THE NARRATIVES OF A HAITIAN WOMAN IN BRAZIL ABOUT THE TEACHING EXERCISE}

\author{
Giovani Giroto \\ Universidade Estatal de Maringá, Brasil \\ https://orcid.org/0000-0001-6683-1075 \\ giovani_giroto@hotmail.com \\ Franciele Clara Peloso \\ Universidad Tecnológica Federal de Paraná, Brasil \\ https://orcid.org/0000-0002-9647-001X \\ fclara.15@gmail.com
}

Recibido: 01-01-2020 Revisado: 10-01-2020 Aceptado: 16-02-2020

\begin{abstract}
Resumen: Este artículo tiene como objetivo reflexionar sobre la identidad del profesor que enseña a estudiantes haitianos en Brasil. A partir de las narraciones de una haitiana residente en la región noroeste de Paraná, fue posible comprender algunos elementos que caracterizan la forma de vida en Haití, los motivos para emigrar, así como identificar características esenciales que debe tener la profesora, o el profesor que trabaja con estudiantes inmigrantes. Identificamos que el maestro para trabajar con inmigrantes necesita comprender que estos estudiantes, además de graduarse, necesitan romper la barrera de la supervivencia. En este sentido, destacamos la importancia de pensar en procesos de formación docente humanizados, que tengan en cuenta la diversidad, la multiculturalidad y la singularidad de las personas sujetos de los procesos de formación, especialmente de aquellas victimizadas por la vulnerabilidad social.
\end{abstract}

Palabras claves: Relatos, migración haitiana, derecho a la educación, formación de profesores.

Abstract: This article aims to reflect on the identity of the teacher who teaches for Haitian students in Brazil. From the narratives of a Haitian living in the northwestern region of Paraná, it was possible to define some elements that characterize the way of life in Haiti and the reasons for emigrating, comparing the identity of the teacher in Haiti and Brazil, and, finally, identifying essential characteristics that the teacher who works with immigrant students should have. We identified that the teacher who works with immigrants needs to understand that these students, in addition to graduating, they need to break the barrier of survival. Therefore, we highlight the importance of thinking about humanized teacher training processes, which contemplate the diversity, multiculturalism and uniqueness of the subjects in the training processes, especially those victimized by social vulnerability.

Keywords: Narratives, Haitian migration, right to education, teacher training.

Cómo citar este artículo: Giroto, G y Peloso, F. C. (2020). Procesos educativos y el derecho a la educación: una mirada a partir de los relatos de una inmigrante haitana en Brasil sobre el ejercicio docente. Hachetetepé. Revista cientifica en Educación y Comunicación, (20), 93-99.doi: http://doi.org/10.25267/Hachetetepe.2020.i20.11 


\section{INTRODUCCIÓN}

Las migraciones han contribuido y continúan contribuyendo a la formación y transformación de la sociedad. Ya sea por cuestiones económicas, culturales, religiosas, políticas o ambientales, entre otras razones. El acto de emigrar no solo afecta a quienes de hecho se mueven geográficamente, sino también a sus descendientes y otras personas de su nuevo entorno social. En este sentido, es importante resaltar que muchas y diferentes personas, a lo largo de la historia, emigraron de sus países de origen y se convirtieron en inmigrantes en Brasil.

En las definiciones de Sayad (1998, p.54) "un inmigrante es esencialmente una fuerza de trabajo, y una fuerza laboral provisoria, temporal y en tránsito". El argumento se apoya en el sentido de que los inmigrantes son personas que no tienen raíces en el lugar donde viven, por lo tanto, "la estadía autorizada al inmigrante está totalmente sujeta al trabajo" (Sayad, 1998, p.55). Es así como la migración se entiende como una condición social de inestabilidad $\mathrm{y}$, en muchos casos, también denota una condición de vulnerabilidad.

Según Almeida (2017), la población de Haití experimentó una dictadura e, incluso en el proceso de redemocratización, sufrió golpes militares, lo que generó inestabilidad económica y política, empobrecimiento y la salida de los haitianos del país. Además, "otro factor que debe considerarse como un impulsor del éxodo de Haití son los desastres naturales que ocurren con frecuencia en el país" (Almeida, 2017, p.57), obligándolos a abandonar su tierra, marcados por "situaciones que muestran la complejidad socioeconómica y política de una población que comienza a luchar por un derecho básico: la supervivencia" (Almeida, 2017, p.72).

Debido a la inseguridad en la que se encuentran estas personas, Brasil, que es uno de los países anfitriones, comienza a otorgar visas humanitarias a los inmigrantes haitianos. Sin embargo, al llegar al territorio brasileño, muchos aún tienen dificultades para salir de la condición de vulnerabilidad, ya que llegan sin garantías laborales o incluso sin el dominio del idioma. Además, también experimentan nuevos conflictos, principalmente debido al prejuicio racial.

Asumir que estos inmigrantes necesitan luchar por su supervivencia, aún en el país de refugio, parece contradictorio. Sin embargo, según Freire (2001, p.15-16) "es precisamente a partir de estas contradicciones que nacen los sueños soñados colectivamente, que tenemos las posibilidades de superar las condiciones de vida a las que estamos sometidos como simples objetos para convertirnos todos y todas en Más Seres."

Para esto, pensar sobre educación en contextos donde se encuentran personas en situación de vulnerabilidad social requiere atención especial y una mirada ajustada a tal situación. De esa forma, este artículo tiene como objetivo reflexionar sobre la identidad del profesor que enseña a estudiantes haitianos en Brasil. Partiendo de las narraciones de una mujer haitiana que vive en el noroeste de Paraná, fue posible encontrar algunos elementos que caracterizan la forma de vida en Haití y las razones para emigrar; comparar la identidad del maestro en Haití y Brasil; y finalmente identificar características esenciales que la profesora y el profesor que actúan con estudiantes inmigrantes deberían tener.

Así, inicialmente, presentamos el camino metodológico que dio origen al material utilizado en el análisis, luego discutimos la profesión docente y finalmente emprendemos un análisis sobre las aproximaciones y fronteras culturales entre Haití y Brasil.

e-ISSN:2172-7910

Doi: http://doi.org/10.25267/Hachetetepe.2020.i20.11

Universidad de Cádiz 


\section{CAMINO METODOLÓGICO: LA CONSTRUCCIÓN DE LETRAS PEDAGÓGICAS A PARTIR DE RELATOS}

Buscamos una metodología que se acercara al máximo al conocimiento popular y permitiera que "la persona misma dijera lo que considera relevante, mientras reflexiona sobre sus experiencias. Esta perspectiva trata a las personas como capaces de ser constructores y participantes de la historia" (Capelle, Borges y Miranda, 2010, p.6). Con este fin, la redacción de cartas pedagógicas por parte de una inmigrante haitiana residente en Brasil representó el recurso metodológico inicial de nuestra práctica en esta investigación.

Souza y Cabral (2015) afirman que la carta es una herramienta pedagógica fácil de usar, su lenguaje está determinado por la intención de lo que se pretende comunicar y por la relación que se pretende establecer. Metodológicamente, las autoras resaltan que las letras pueden ser descriptivas, persuasivas-argumentativas y/o narrativas, dependiendo de su intención.

En efecto, la carta de este trabajo puede definirse como una narrativa, ya que aporta en su contenido información sobre la historia de vida personal y profesional del sujeto investigado. El sujeto al que nos referimos es una inmigrante haitiana.

La inmigrante participó como estudiante en una clase de estudios preparatorios para el vestibular (examen de ingreso a la Universidad). La iniciativa del grupo de estudio provino de una solicitud de la asociación de inmigrantes del municipio. La institución informó que algunas haitianas se habían inscrito en el examen de ingreso y que los candidatos necesitaban ayuda con sus estudios, así como orientación técnica sobre la organización de la prueba y cómo completar las hojas de respuesta. A partir de este pedido, esta clase recibió ayuda los sábados, de parte de uno de los investigadores, como voluntario. Luego de conversaciones informales sobre las diferencias y semejanzas entre Haití y Brasil, invitamos a una estudiante a escribir una carta que contara su historia de vida, las diferencias entre la escuela y los profesores de su país de origen y su país anfitrión, y las principales características que le parecían necesarias para un profesor que enseñara a inmigrantes.

Es importante resaltar que la estudiante no dominaba la escritura de la lengua portuguesa. Por ese motivo, optamos por abordar los mismos temas basados en los relatos como método, ya que eso "le permite al narrador contar la historia sobre algún acontecimiento relevante de su historia de vida y del contexto del que forma parte" (Sousa y Cabral, 2015, p.154). Luego, el relato grabado en audio, con la autorización de nuestra entrevistada, fue transcripto de acuerdo con la identidad de habla de la estudiante, lo que no acarreó alteración de contenido, únicamente de forma.

A partir de estos procedimientos metodológicos para la recolección de datos, pudimos conocer más sobre la historia de la estudiante y su país de origen, así como las comparaciones entre ambos países sobre las principales características que necesita un profesor para enseñar a inmigrantes.

\section{SER PROFESORA, PROFESOR: DISTINTAS IDENTIDADES, MÚLTIPLES CONTEXTOS}

Es válido considerar que hay una única definición de profesora o profesor. Se trata de una profesión que se traduce de múltiples maneras de acuerdo con el público del que ese profesional forma parte. Tiene su variación de acuerdo al contexto, al tiempo, los 
recursos, la lengua, la formación, entre muchos otros factores que se suman y resultan en diferentes y distintas formas de ejercer la profesión.

De acuerdo con Arroyo (2000) existen diferentes perspectivas sobre la actuación pedagógica, muchas veces caracterizada por la edad de los estudiantes, su condición económica o incluso el contexto social. Estas variaciones producen imágenes y autoimágenes de estos profesionales que componen sus historias, experiencias y formas de enseñar y aprender.

En efecto, subrayamos que el lugar de la docencia es un lugar plural, un lugar de relaciones humanas, de lectura del mundo y de promoción de la humanización. Sin embargo, es necesario reflexionar y valorar ese lugar, pues aún con atribuciones específicas y objetivas, enfatizando los saberes técnicos que apuntan hacia el conocimiento estructural contenido en los libros didácticos, y $\sin$ el debido reconocimiento diario en su profesión, aun así las profesoras y profesores tienen el potencial de promover humanidad, conocer, mantener y recrear la cultura, y considerar a cada estudiante y a sí mismos en los procesos históricos en los que participan.

Desde nuestra mirada sobre las narrativas de la inmigrante haitiana, buscamos hacer un análisis humanizado de los problemas compartidos con el objeto de reflexionar sobre el papel de la profesora y el profesor en el proceso de inclusión social de los inmigrantes. En efecto, extractamos algunos tramos de las narraciones para apoyar nuestro análisis y reflexión. La identidad de la inmigrante será preservada, llamándola con el seudónimo Etana, elegido por ella.

Etana tiene 25 años, nació y creció en la capital de Haití, Puerto Príncipe. Vino a Brasil a pedido de su tío, que ya vivía en el país anfitrión. Esperaba seguir estudiando y mejorar su vida. En una de sus cartas, ella cuenta que:

Al principio vivía solo con mi madre. Mi padre está separado de mi madre. Luego viví con mi madre, mi padrastro y mi media hermana. Estudié todo el tiempo en una escuela privada y fue mi madre quien hizo todo. Después conocí a mi padre a la edad de 15 años y a los dos meses falleció. Estudié desde que era pequeña hasta los 18 años. Hice todo, todo, todo, lo de la clase. Luego comencé a trabajar y fui a la universidad y después de tres años mi tío me pidió que viniera aquí (Brasil) Dejé la universidad y vine para acá. Llegué a Brasil y descubrí que estaba embarazada. Aquí no tengo trabajo formal y tampoco estoy en la universidad. Ahora llevo 2 años y 3 meses aquí y quiero estudiar más (Etana, 2018)

El contexto familiar está marcado por la figura de la madre como central. Después de decir que los padres estaban divorciados, ella afirma que la madre era la principal responsable de su educación. La relación familiar está marcada por la convivencia con el padrastro y su hija, así como por la muerte del padre, que en la presentación fue considerada un hito en su trayectoria. En otro relato, Etana cuenta que en Haití se inscribió en un curso de educación superior, y llegó a ejercer el cargo de asesora de una candidata a diputada. Sin embargo, debido a la condición de inestabilidad que afecta al país, a la necesidad de auxiliar a su tío, y gracias a las facilidades que daban las políticas de migración hacia Brasil, Etana decide emigrar hacia el país anfitrión con la esperanza de ampliar aún más sus posibilidades $\mathrm{y}$, sobre todo, de escapar de la condición de inestabilidad en su país.

Según Joint (2008, p. 189): "entre el 34\% y el 40\% de los niños de Haití todavía no tienen acceso a la escuela". Además, una de las fuertes características del sistema 
educativo de Haití es la privatización de la enseñanza, que marca una separación entre clases sociales. Como afirma Joint (2008), en Haití las escuelas nacionales siempre han sido pocas, y mayormente frecuentadas por la clase rica. En su narración sobre su escolarización en Haití, la estudiante indica que su formación tuvo lugar en escuelas privadas. Como Haití es un país con altas tasas de ciudadanos sin escolarización, vemos que la condición social de la estudiante en Haití no era vulnerable, porque tenía acceso a la educación privada y podía leer y escribir en un país donde casi la mitad de la población no tiene acceso a la escuela.

Aun así, si su pasado no estuvo marcado por una condición de vulnerabilidad, su presente apunta a tal escenario, ya que en Brasil no tiene trabajo formal ni acceso a la educación superior, como tenía en Haití. A parte de eso, todavía existe el hecho de que allá era hija y aquí se convirtió en madre, una responsabilidad más en su lucha por una vida digna en Brasil.

El relato de presentación también está marcado por el deseo de estudiar y seguir una formación académica en Brasil. Al hablar de su relación con la escuela, de los profesores, y también sobre la educación en Haití, ella anuncia que:

La verdad es que amo a la escuela y a los profesores y también a los amigos. Ellos quieren que te interese la escuela, las actividades, y si no quieres estudiar, te pegan. No, no es fácil. En la universidad no es así, pero a veces piden que vengas con un familiar a la reunión. Ellos piden conocer a tus parientes. No puedes salir cuando quieras, no puedes venir con lo que quieras, por ejemplo unos pantalones cortos. Y no quieren a los hombres con el cabello trenzado. Bastantes cosas, pero es bueno. Tienes que seguir las formas para ir a la escuela. No te puedes perder la clase. Si la pierdes tienes castigo. Si el curso termina a las 4 horas, permanecerá hasta las 6 horas. Tendrás una hora y media para leer el libro y luego hacer un resumen. Es difícil... (Etana, 2018)

El aprecio hacia la escuela se muestra ya en el comienzo de su discurso, cuando hace consideraciones sobre el espacio escolar y, también, sobre los profesores. Pero también hace mención a las dificultades enfrentadas en la enseñanza haitiana, como por ejemplo, el autoritarismo de los profesores, que permite inclusive agresiones físicas, justificadas por el propósito de hacer que el estudiante se enfoque en los estudios durante la educación básica. Otra información importante es la proximidad con la familia, incluso en las instituciones de educación superior.

La rutina de un estudiante de pregrado se presenta, en el discurso de Etana, como muy regulada. Se percibe una conducta específica esperada por los estudiantes de pregrado, que abarca desde la ropa, el cuidado con la higiene y estética personal, hasta la rigidez en la frecuencia y puntualidad. En los casos en que no se cumplan tales reglas, se aplican castigos con fines educativos y formativos.

Haciendo la comparación con la educación en Brasil, desde su perspectiva, vemos que:

Aquí es muy diferente, ¿sabes? Diferente porque realmente amas lo que haces, me diste tu tiempo, no tienes prisa para terminar, pero si voy a la escuela de verdad ellos tendrán prisa para terminar el libro, ¿entiendes? Y mi amiguita (la profesora de portugués) también me dio su tiempo, su apoyo, me dijo: "puedes decir esto, no puedes decir aquello". Después, en la escuela hice un curso técnico. Fue genial, pero no tenía un profesor de verdad que me enseñara. Yo iba, me ponía mis auriculares y trabajaba sola en 
la computadora. Solo si tuviera alguna cosa para preguntar, entraba en la administración y le pedía a alguien y venía, me enseñaba y acababa (Etana, 2018)

El afecto y la estima por la profesión son puntos señalados como diferentes entre la educación haitiana y la brasileña. Las referencias docentes en Brasil se reflejaron en dos casos de educación en espacios no escolares, ya que el único contacto con una educación más formal fue posible en una institución de educación a distancia, en la que la estudiante se vio sola frente a su formación.

Un punto que llama nuestra atención es la gratitud que la estudiante tiene en relación con el tiempo que le dedican sus profesores. Esta cualidad es lo que distingue a estos maestros de aquellos que trabajan en instituciones escolares, definidas por la estudiante como "escuelas reales".

Finalmente, además de distinguir las formas de educación, la alumna menciona a la profesora de portugués como su "amiguita" mientras que, en el mismo extracto, hace referencia a los "profesores de verdad". Esa separación tiene origen en la forma de enseñar, la relación entre profesor y alumno y también en el espacio físico en el que se imparten las clases. La enseñanza no formal es recibida de forma positiva por la estudiante, ya que ella indica la efectividad de esa forma de educación en la atención a las necesidades más urgentes y más personales, mientras que la enseñanza formal, en la perspectiva de Etana, atiende a un contenido programático sin mirar, de forma individual, a quién se destina.

Una última propuesta de registro solicitada a la estudiante era que expresara qué características esenciales debería tener un profesor brasileño para enseñar a inmigrantes. A partir de eso, comenzamos a construir la identidad del profesor. Etana expresa que "en verdad, puede ser un profesor igual al profesor de los brasileños, pero va a tener problema para conversar con nosotros. Yo creo que el profesor tendría que hacer un curso de la otra lengua para aprender a hablar con los alumnos" (Etana, 2018).

Ella sostiene que no hay necesidad de tener un profesor específico, diferente, por ellos ser inmigrantes, sin embargo, enseguida señala a la lengua como un factor que perjudica a la comunicación, y consecuentemente, a la comprensión que el alumno tiene de los contenidos mediados por el profesor. Más adelante, la estudiante consideró que los profesores brasileños

Tienen que ayudar a leer y escribir también, ¿se entiende? Pero el portugués es difícil de hablar. Ellos tienen que comenzar por la base, aprender los verbos, el alfabeto, hacer esas cosas. Si usted hace esas cosas yo voy a conocer como se habla y como se escribe también. Es sólo decirme "esa es la televisión, esa es una cosa, esa cierra, esa abre", enseñarme cómo voy a hacer para hablar. Tiene que tener bastante paciencia para ayudar. Si va a enseñarme alguna cosa yo voy a tener un problema para entender rapidito, pero si Dios quiere... ipuede ser! Pero si el profesor no tiene paciencia, no va a poder ayudarme de verdad. Va a decirme "ah, tú no sabes nada". Para todo, hay que tener paciencia, ¿no? (Etana, 2018)

Etana presenta por segunda vez argumentos que denotan un aprendizaje técnico, mucho más asociado al entrenamiento que a la enseñanza. La primera de ellas, al citar la profesora de portugués, que orientaba sobre las cosas que ella podría o no decir, y ahora, al describir hipotéticamente la actuación de un profesor que enseña la lengua nacional 
brasileña. Tal impresión se entiende por la urgencia que siente por aprender la lengua y demás conocimientos de forma rápida, pues también es una cuestión de supervivencia.

La relación profesor-alumno precisa ser colaborativa, respetuosa y también compuesta por afecto. Un profesor no puede considerar el aprendizaje efectivo de un estudiante si no tiene en cuenta el tiempo necesario para que ese alumno aprenda, si no hay una comunicación colaborativa, y si no hay confianza. Cabe al profesor el [...] "cultivo de la sensibilidad y paciencia pedagógica para esperar los tiempos del aprender" (Arroyo, 2009, p.29).

Finalmente, la alumna termina con la siguiente consideración: "creo que las características del profesor, entonces, necesitan ser paciencia, tolerancia y apoyo" (Etana, 2018). En ese sentido, rescatamos una definición de Freire (1997) al anunciar que "la tolerancia es la virtud que nos enseña a convivir con el diferente. A aprender con el diferente, a respetar al diferente" (Freire, 1997, p.39). O sea, en las relaciones pedagógicas, convivimos con los diferentes, porque en nuestro medio social también es así. Ser tolerante y posibilitar respeto y empatía con el otro es una condición imprescindible de la identidad del profesor.

\section{ALGUNAS CONSIDERACIONES}

Frente a lo expuesto, podemos destacar que en sus relatos, Etana nos cuenta sobre su trayectoria escolar en Haití y afirma que quiere continuar sus estudios en Brasil, un sueño posible. Observamos en nuestros análisis una consideración favorable hacia los ambientes escolar y universitario, así como un cariño y respeto por el papel que el profesor ejerce. Al comparar la educación haitiana con la brasileña, la estudiante destaca el afecto de los profesores brasileños como un factor positivo, ya que en Haití los profesores tienen una conducta más autoritaria.

Así, retomamos nuestra pregunta inicial: ¿Cuál debería ser la identidad del profesor que enseña a estudiantes haitianos en Brasil? A partir de las vivencias e ideas de Etana sobre su formación, vemos que en un primer momento defiende que no debería haber diferencias entre el profesor que enseña a brasileños o extranjeros. A partir de eso, concluimos que los extranjeros que tienen a Brasil como país anfitrión no quieren servicios diferentes de aquellos ofrecidos a los brasileños, o sea, quieren ser tratados de forma igualitaria. Sin embargo, cuando tenemos en consideración todos los desafíos y percances diarios de los haitianos entendemos que ofrecer la misma enseñanza no es sinónimo de igualdad.

Ese tratamiento igualitario solicitado por Etana, nos hace pensar en el concepto de unidad en la diversidad, propuesto por Paulo Freire. Según Freire (1993), las diferencias interculturales existen y presentan cortes: de clase, de raza, de género, y esas diferencias generan ideologías, por un lado, discriminatorias y, por otro, de resistencia, que en función de su experiencia de lucha, derivan en formas de comportamiento más o menos pacíficas, o rebeldes. En ese sentido, la idea de unidad en la diversidad es una formulación ética que implica el reconocimiento de que somos diferentes y no podemos negar esas diferencias; pero por detrás de esas diferencias, hay algo que nos unifica, que es nuestra igualdad fundamental, nuestra humanidad, y la lucha contra todas las dominaciones.

\section{REFERENCIAS BIBLIOGRÁFICAS}

Almeida, C. D. (2017). Haitianos no Brasil e sua relação com a comunicação, o consumo e o trabalho. São Paulo: Paulus. 
Arroyo, M. G. (2000). Ofício de mestre: imagens e auto-imagens. Petrópolis. Rio de Janeiro: Vozes.

Arroyo, M. G. (2009). Imagens quebradas: Trajetórias e tempos de alunos e mestres. Petrópolis: Vozes.

Capelle, M. C., Borges, C. L. P. y Miranda, A. R. A. (2010). Um Exemplo do Uso da História Oral como Técnica Complementar de Pesquisa em Administração. En Anais do VI Encontro de estudos organizacionais da ANPAD; 1-13. Disponible en: <http://www.anpad.org.br/admin/pdf/eneo117.pdf >

Freire, P. (1989). Educadores de rua: uma abordagem crítica: Alternativas de entendimento aos meninos de rua. Bogotá: Gente Nueva.

Freire, P. (1993). Anotações sobre Unidade na Diversidade. En P. Freire Política e Educação (pp.31-36). São Paulo: Cortez

Freire, P. (1997). Pedagogia da Esperança: Um reencontro com a Pedagogia do Oprimido. Rio de Janeiro: Paz e Terra.

Freire, P. (2001). Pedagogia dos sonhos possíveis. São Paulo: UNESP.

Joint, L. A. (2008). Sistema educacional e desigualdades sociais no Haiti: o caso das escolas católicas. Revista Pro-Posições, 19(2), 181-191.

Sayad, A. (1998). A imigração ou os paradoxos da alteridade. São Paulo: Editora da Universidade de São Paulo.

Sousa, M. y Cabral, C. (2015). A narrativa como opção metodológica de pesquisa e formação de profesores. Revista Horizontes, 33(2), 149-158. 